\title{
Riverscape genomics of cichlid fishes in the lower Congo: Uncovering mechanisms of diversification in an extreme hydrological regime
}

\author{
Naoko Kurata ${ }^{1}$, Michael Hickerson ${ }^{2}$, Sandra Hoffberg ${ }^{3}$, Ned Gardiner ${ }^{4}$, Melanie L.J. \\ Stiassny ${ }^{1}$, and S. Elizabeth Alter ${ }^{1}$ \\ ${ }^{1}$ American Museum of Natural History \\ ${ }^{2}$ City University of New York The Graduate Center \\ ${ }^{3}$ Columbia University \\ ${ }^{4}$ University of Georgia
}

November 16, 2021

\begin{abstract}
Rivers provide excellent models to understand how species diversity is generated and maintained across heterogeneous habitats. The lower Congo River (LCR) consists of a dynamic hydroscape exhibiting extraordinary aquatic biodiversity, endemicity, and ecological specialization. Previous studies have suggested that the numerous high-energy rapids throughout the LCR form physical barriers to gene flow, thus facilitating diversification and speciation, and generating ichthyofaunal diversity. However, this hypothesis has not been fully explored using genome-wide SNPs for fish species distributed across the LCR. In this study, we examined four species of lamprologine cichlids endemic to the LCR, of which three are sequentially distributed along the LCR without range overlap. Using genome-wide SNP data, we tested the hypotheses that high-energy rapids serve as physical barriers to gene flow that generate genetic divergence at inter- and intraspecific levels, and that gene flow occurs primarily in a downstream direction. Our results are consistent with the prediction that the rapids sometimes serve to reduce gene flow, but also suggest that at certain temporal and spatial scales, they may also act as promoters of gene flow. Furthermore, we detected both upstream and downstream gene flow between some populations of Lamprologus tigripictilis as well as hybridization between congeneric species. These results suggest that powerful high-energy rapids may therefore provide occasional multidirectional dispersal opportunities for riverine cichlid fishes, highlighting the complexity of factors driving evolutionary processes in the LCR.
\end{abstract}

\section{Hosted file}

Manuscript_ME.docx available at https://authorea.com/users/446553/articles/545739-riverscapegenomics-of-cichlid-fishes-in-the-lower-congo-uncovering-mechanisms-of-diversificationin-an-extreme-hydrological-regime 